\title{
3 Theory of offshoring of advanced business services
}

\subsection{Specifics of theorising on offshoring}

Offshoring of services is a younger sibling of the relocation of manufacturing processes abroad. It is directly reflected in the theoretical approaches to explaining both the tangible and intangible forms of offshoring. There are many similarities between them. In the beginning they were about cost reduction and access to capacity. Moreover, offshoring of white-collar jobs or offshoring of knowledge-based tasks, especially in its nascent stage, was rather about repetitive tasks, where the input of the brainpower of a human being was limited.

Anyway, both types of offshoring underwent significant changes making the technology, knowledge, process excellence indispensable elements. Therefore, the presentation of the theoretical framework will employ approaches created both for offshoring in general and those specific to knowledge-intensive services. Actually, the original theoretical background created to explain the manufacturing operations has been supplemented with elements directly related to services. Due to the rising complexity of tasks and greater expectations towards units providing the offshoring solutions, the divergence between manufacturing and services became wider.

We agree with Bunyaratavej et al. (2011) that the theoretical approach to offshoring of services requires an update and modification. It has been some time since their conclusion, but neither the universally accepted approach to the whitecollar offshoring emerged nor the existing approaches coped adequately with the changes in the services offshoring. Especially the latter issue brings challenges to the theorists of economics and management. The inadequacy of the theoretical conceptualisation of ABS has been also pronounced for the recent developments in offshoring in both emerging and advanced Asian economies (Jones \& Ström, 2018). This is due to the distinctive characteristics of the institutional, socio-cultural and corporate contexts in local economies, but also as a result of global interconnections.

The theoretical framework of offshoring of services, in comparison to manufacturing, is very different when it comes to the trade costs. Physical goods require costly and time consuming transportation, what makes them prone to trade barriers. When it comes to offshoring of services, it is much cheaper and faster to transfer the knowledge using the digital communication infrastructure. It is also more difficult to design trade policy tools that will stop the transfer of such services across borders.

Besides the implicit economic costs, there is a new set of externalities related to the issue of offshoring, such as the costs to the natural environment. The issue of pollution due to transporting the goods over large distance is very important. Such 
a situation does not concern the offshoring of services. Naturally, there is a certain level of emissions due to ABS operations, however it is present irrespective of the country of execution of the activities. Actually the modern technologies and commoditisation of the services reduces the necessity of personal contacts, so the emission due to long journeys should be also reduced. This is the element that requires more attention in the literature, and especially in the theoretical framework.

We also argue that there is no framework, which can accommodate both business and economic approach. From the idealistic point of view, an economic model of offshoring should put in a broader context the assumptions of a business model, which explains offshoring inside a business organisation. Such approaches can be observed in international economics and international business regarding some other issues, such as foreign direct investment. However, the theory of offshoring is so vague that is impossible to find the common ground. The goal of the chapter is to review recent developments in economic and business theory of offshoring and try to find the potential common elements.

Offshoring has been predominantly considered as the transfer of tasks from high-cost to low-cost economies. However, this should be considered in the broader context. The issue that should be addressed in the theory is the hybrid form of offshoring. By the word hybrid we mean a situation in which a firm, which specialises in the offshore outsourcing provisions for foreign clients, is also present in the home economy of the client. The flexibility of organising their operations due to the intangible nature of services means that they are present in various locations. For example, Indian companies, which provide services to clients in the United States have been attracted to invest in this economy in order to access knowledge sources, legitimate their presence in the industry and commission still more orders in the market (Ricart, Pisani, Agnese, \& Adegbesan, 2011).

The issue, which is crucial in the theory of offshoring are time zones. The necessity to organise processes $24 / 7$ makes it inevitable to fragment the provision of services in a few distant locations. One of the models adopted by Indian firms is to provide two shifts from India and the third one either from Mexico (for American clients) or from Africa (for European clients). The theoretical model provided evidence that under monopolistic competition, the existence of time zones reduces costs of services offshoring and makes such an option more profitable for firms offshoring the activities, but also for providers of the services (Kikuchi \& Long, 2010). They also argue that the welfare effects of services offshoring may be negative due to the increased waste in firms becoming providers of offshore services. Anyway, offshoring due to the time differences may be profitable due to the necessity of organising process $24 / 7$.

Conversely, relocating the tasks to a different time zone may increase welfare due to reducing the necessity of night shifts, thus avoiding higher costs and higher shift disutility (Matsuoka \& Fukushima, 2010). In such a setting home country 
workers do not need to work night shifts, but at the same time foreign workers in different time zone are also working during their day. However, there is a necessity that services delivered by a foreign provider are not consumed immediately (as for example call centre services). Such a situation is possible thanks to technology.

The arguments that time zones create business opportunities present only one side of the phenomenon. Actually, the time differences between economies may be treated as a form of a trade barrier. This is especially the case for provision of business services that require some level of interaction between employees in various locations. Time differences make such contacts more difficult or at least one side should adjust working time to the other side. This is the case for many Indian and Philippine call centres working night shifts in order to contact American clients.

In general, the time differences should be seen from two perspectives. First, the time differences between the headquarters and a unit providing services from abroad. Then it should be more favourable for a firm to establish a service unit in an economy of the same or similar time zone. Second, the perspective of contacts between a service unit and its clients - other subsidiaries of a MNE. Time differences are partly responsible for creating on particular continents the regional business centres, which operate in their time zones, thus the communication is easier. This is particularly important from the perspective of CEE as a host location. Sharing the same time zone with the large part of the Western Europe is one of the main advantages. This also partially explains why, in spite of much higher costs than in many Asian economies, offshoring of services is located in CEE. This also suggests why many American multinationals moved processes to CEE in order to serve the region of Europe and Middle East. On the whole, in spite of some theoretical proposition, the time differences should be still treated as an obstruction to the seamless provision of white-collar services across borders.

All in all, building a universal model of offshoring of advanced business services is not possible now. It is due to the vast diversification of services that are offshored, evolution (or even revolution) of ABS, and differences between key offshoring destinations. India is rather the case for outsourcing operations with the large role of domestic dominant firms. The Philippines focus on voice services and some niche services. V4 is rather a relatively high-cost location with focus on a spectrum of various business functions. There is also the issue of offshoring and nearshoring. India and the Philippines are selected by firms from distant locations (e.g. the US or the Europe). V4 economies are selected predominantly by EU firms looking for lower costs, but also sharing similar culture and institutional environment. Therefore, the models rather explain regional characteristics of offshoring in Europe or Asia, but do not comprehend the global perspective. 


\subsection{International economics and services offshoring}

The phenomenon of offshoring of services has been well rooted both in international economics (IE) and international business (IB). Naturally, the level of analysis is different as IE tries to explain rather economy-wide determinants and results, while IB focuses on the decisions of firms and their international organisation. However, both approaches have common propositions and main objects - multinational enterprises. It is also argued that ABS are prerequisite condition of a truly global MNE (Jones A., 2005). In line with his idea, the level of multinationality of a firm should be considered through its corporate globality, which may help to understand the relationship between a firm and territorial spaces.

There are arguments that the theoretical approach used for international trade or foreign investment is not suitable for explaining the offshoring operations. According to Kshetri (2007) differences with traditional approach stem from: newness, which implicates lack or limited regulatory framework; more direct substitution for jobs in home economy; a higher degree of interactions between home and host country operations. Such arguments are amplified for offshoring of services that are knowledge-intensive.

When it comes to newness it is not only the fact that many aspects of whitecollar jobs offshoring have not been sufficiently explained. It is rather connected to the fact that when the manufacturing activities are offshored, it means moving the existing processes abroad. In the case of knowledge-intensive business services, it is mostly about profoundly transforming or developing new activities abroad instead of at a home economy. The tasks are frequently created abroad from the very beginning and are also of a different nature - frequently optimised for machine execution.

The issue of international trade in services within MNEs has been already discussed in the late 1980 s by Markusen (1987). His direct aim was not to discuss offshoring of services, however he brought the crucial elements for future understanding of the operations of MNEs with respect to services. First, he treated the producer services as jointly delivered to many units of MNEs. It meant that there were economies of scale and a two-plant enterprise was more efficient that two separate firms. His ideas well fit the current state of development of shared services centres, which are aimed at delivering services to numerous units of an enterprise. The ideal situation would be if all supporting services could be served from one central unit to all business units, thus sharing the costs.

One of the first approaches to conceptualise the offshoring of white collar jobs was also presented by Markusen (2005). Besides analysing home economy effects, he introduced factors influencing host countries. According to his approach, the offshoring is not harmful neither for a home nor host economy. Indeed, the positive effects of offshoring were analysed from the point of view of employees' situation in a home country once the processes had been moved abroad. Markusen confirmed 
that workers made redundant due to offshoring might be employed in more productive industries in the home country. On the other hand, thanks to offshoring of whitecollar jobs, the qualifications of host country workers will be utilised. Otherwise, they would not find suitable jobs and their skills would be wasted. We could generalise that in home economies there is room for companies offshoring processes and in host economies there is room for new foreign entrants. The job market will remain balanced.

The IE perspective on offshoring has been well explained by Grossman and Rossi-Hansberg (2008). Nonetheless, they have not focused purely on services, but introduced to the literature the notion of "trading tasks", which encompasses both material and service activities. It means that production processes can be divided into tasks and then fragmented internationally. Their theoretical framework allows for analysing the changes in factor prices in the home economy as a result of offshoring. They listed three effects related to offshoring: productivity effect (results of home country specialisation), the relative price effect (relatively cheaper goods) and labour-supply effect (impact on labour market). Trade is task may be also an important view on potential of robotisation of service tasks.

The specificity of trade in services has been explained by Markusen and Strand (2009). Their departing point was listing the barriers to trade in services, which make this trade different from the one in manufacturing goods. The barriers impose the mode of serving a foreign market with services. The authors did not focus specifically on ABS, but rather on any type of business services. Importantly, they took into consideration FDI and the role of MNEs in the international flows of services. Their study enriched understanding of MNEs with respect to services. One limitation is the they did not distinguish between captive offshoring and offshore outsourcing.

Grossman and Helpman (2002) focused on the contracting environment to explain decision about outsourcing to the North or South. Generally, outsourcing contracts are incomplete, with limited possibilities to verify the investment by partners. Such a framework could be also extended to offshoring to locations differentiated by the quality of the legal environment. This is associated with the risk of offshoring arrangement. The fixed costs of establishing a service unit abroad are much lower in comparison to manufacturing operations. However, the main risk is associated with data that are processed by the offshore units. Therefore is some industries, like banking, there are limited possibilities to contract out some processes due to the risks and legal barriers.

\subsection{International business and service offshoring}

From the IB perspective, the academic attention on the issue of offshoring has taken off after 2000, with numerous publications in the period 2010-2014 (Pisani \& Ricart, 2015). This was also the result of the high tide of offshoring projects, as well as the 
attention of policymakers and the general public. However, many explanations of the offshoring phenomenon can be described as ad hoc.

When analysing this strand of theory, the starting point should be the OLI paradigm by Dunning (1988), which explains the international expansion of a firm using the dimensions of ownership, location and internalisation. The Dunning's original model has been designed for manufacturing firms, therefore including a dimension specific to knowledge-intensive business services was bringing the model to the business reality. Graf and Mudambi (2005) in their analysis of offshore outsourcing added human capital to the benchmark model.

Moreover, the OLI model treats a firm's advantages in a static way, while the current global business environment requires dynamism and creation of advantages is a result of cooperation within a network (Contractor, Kumar, Kundu, \& Pedersen, 2010). Graf and Mudambi (2005) besides factors pertaining to locations of outsourcing, also included qualities of firms active in foreign service operations, such as outsourcing objectives and experience. However, in the literature the dominant empirical approach uses the firm-level or multiple levels of analysis, but not a multilevel approach (Pisani \& Ricart, 2015).

The framework of offshoring has been created to answer the question about what brings firms to move some of their processes abroad. Companies engage in offshoring when they perceive advantages in three main areas: disintegration advantages (D), location-specific resourcing advantages (L) and externalization advantages (E) (Kedia \& Mukherjee, 2009). The model was also an extension of the OLI model. One element, the location was the same as in the original form, however the remaining factors took the opposite direction. First, the issue of disintegration was underlined. Many tasks, especially those related to KIBS, could be successfully separated from other business functions of an enterprise. But even more evident is the possibility of externalisation. This gives ground especially to offshore outsourcing, so the activities can be more efficiently executed by an external foreign partner, than a provider in home economy. The model has taken into consideration both manufacturing and services, however the main point was about modern offshoring of intangible business processes.

The literature survey also provided insight into the approach taken by researchers. They applied the headquarters - client perspective (Pisani \& Ricart, 2015). This might be explained by the dominant and decisive role of the headquarters in arranging outsourcing contracts or establishing a shared services centre. This is also important because the initiative of transformation has to emerge in the headquarters (or at least be imposed by the top management).

However, when analysing the headquarters-subsidiary relations, we also need to mention the evolution of the structures of MNEs towards more autonomy of geographically dispersed units. It means that ABS subsidiaries and even the contractual outsourcing providers should be considered as valuable partners for the headquarters in the development of the entire organisation. It is important to go beyond the traditional 
top-bottom approach. There should be a kind of network approach, with each member of the network having a relevant role to play. This is especially important when we take into consideration that ABS units should provide the knowledge-intensive content. Anyway, as it was earlier mentioned, the knowledge intensity of business services still varies significantly.

Consequently, ABS units should play much bigger role than just providing the transactional services. This is associated with the evolution of ABS towards more value added operations. When it comes to knowledge creation within a MNE, there are two opposite views with respect to offshoring, but the outcome should be the same - more knowledge. The opposite views can be linked to the theoretical approaches aiming either at internalisation or contracting out business activities.

There are strong arguments for internalising the creation of knowledge within the structures of a MNE. Incorporating ABS units into the structures is a way of improving their efficiency and at the same time the operations of the entire organisation. This is due to the fact that knowledge is difficult to be enforced by contracts (especially those of an imperfect form) with external partners. Anyway, there should be also a distinction between tasks that are rather transactional in form and those of higher intensity of knowledge utilisation.

We use here the notion of tasks, instead of services, as more granular approach is required. Within the process of delivering services, there might be tasks of higher knowledge content, which can be executed internally and those pieces of transactional type, which can be processed in any low-cost destination. Not only the knowledge content is crucial, but also the sensitivity of information. For example, the production process of a car component does not need any personal data. But processing payroll data or health data contains loads of very sensitive information. Therefore, firms should opt for internalisation of processing such data. The issue is also cybersecurity. Importantly, more and more information has been stored about individuals and firms in various, frequently connected systems, that may be potentially hackable.

The issue is that due to commoditisation of services, they are treated from the physical perspective as merely carriers of the information, not the content itself. Gigabytes of data have been treated as tons of goods exported. In the monetary term, the value of services has been calculated. But it has very little in common with the real value of data for firms or individuals. Due to the differences in the legal environment between countries and also the human factor, it is difficult to keep knowledge within boundaries of an organisation. Therefore the discussion between internalisation and externalisation of services should be seen in the broader context.

The issue of protecting knowledge when it comes to offshoring of knowledgeintensive processes is only one side of the matter. But even more complex is establishing an ecosystem that will stimulate the creation of the knowledge in the international environment. 
The successful knowledge creation requires internationally coordinated units. Thus offshoring may foster the formation of knowledge and new competences of a firm by tapping talent pools in various locations. This is also the case for offshore outsourcing, as firms can access not only their proprietary foreign knowledge capacity, but also resources of other organisations. Indeed, global outsourcing allows to access worldwide sources of knowledge (Verwaal, 2017). So, both outsourcing and offshoring are important sources of knowledge, however they have some limitations. This should be also seen from the perspective of the type of knowledge that is searched abroad. If a firm searches for similar and competitive to the existing knowledge abroad, it is known as the knowledge exploitation, but if a firm aims at accessing knowledge from new areas that are distant to the existing resource, it is known as knowledge exploration (Mukherjee, Lahiri, Ash, \& Gaur, 2019).

It is also important to analyse decision-making by firms about engagement in offshoring and selecting the location for the activities. It is postulated that the decision about choosing an optimal location depends on the characteristics of a host economy, but at the same time it should be aligned with the strategy of a firm (Jensen \& Pedersen, 2011). Moreover, there is a need to distinguish between the standard routine activities and those of high knowledge content as this highly influences the location choice.

\subsection{Transaction costs approach to offshoring}

The approach, which is particularly useful and frequently applied to explaining the issue of captive offshoring and offshore outsourcing, is the transaction costs theory. Its foundations, laid by Coase (1937), explained the existence of a firm as a way to avoid the transaction costs by internalising processes. The transaction costs mean the additional expenses that need to be added to the price of goods or services. The transaction costs usually arise due to searching for information, bargaining, or enforcing the contract between parties in a marketplace. Williamson (1981) extended the discussion on the transaction costs and investigated the structure of a firm. He explicitly asked about which activities should be performed within a firm or outside it, and also why. This gives a rise to the analysis of the profitability of outsourcing.

Until now we have been studied the theoretical framework for offshoring in the broad sense of the phenomenon. It means that both activities of captive business centres and business process outsourcing have been put together and the integrated framework was provided. Anyway, to fully understand and cope with the complexity of business services, it is worth introducing a separate treatment of outsourcing. Till now we have also applied two main levels of the analysis - economies and firms. However, it is argued that besides considering locations and firms, it is also important to introduce process-level factors to understand location distance and governance model choice (Gerbl, McIvor, Loane, \& Humphreys, 2015). Their major 
alteration to the existing theoretical framework was also introducing a possibility of local and nearshore outsourcing. It increased the complexity of the framework, however it was brought much closer to the reality.

Due to the increased global competition and the need to transform the structure of a firm, offshoring and outsourcing are used to perform also core processes of enterprises. Therefore the boundaries of many firms shrank organisationally (many processes have been outsourced) and expanded geographically (many processes have been offshored) (Contractor, Kumar, Kundu, \& Pedersen, 2010). This is an important extension of the theory as the two solutions offer still lower transaction costs. The focus on outsourcing and offshoring is also considered in a broader context of corporate restructuring and vertical disintegration of firms (Massini \& Miozzo, 2012). However, the picture of modern MNEs is more complex and this is no longer about a simple choice between performing processes in-house or by an external partner. This is also not solely about considering domestic and international sourcing. All of these possibilities have to be considered simultaneously in order to execute a cohesive global strategy. Therefore, when we return to the main issue of transaction costs economics, which is about the boundaries of firms, we should perceive them in the global context and include various contractual partners.

Besides the expected gains from offshoring, there are various drawbacks and hidden costs of moving the activities abroad. This is particularly important for ABS, as they include interactions between stakeholders from different countries. It is easier to manufacture the same physical item of the same quality in an offshore destination as in a home country and any differences cannot be spotted (besides the label "Made in ... "). But the execution of sourcing knowledge-intensive activities may be dramatically different between particular locations. One of the important elements are cultural differences (e.g. language, education) between providers and users of the service. Thus, it all increases the transaction costs.

The hidden costs of offshoring may also result in failing to meet the expected outcomes (Zheng \& Wang, 2017). From the business perspective, it increases the costs of such operations, therefore the threshold above which a firm is capable of being engaged in offshoring is higher. It means that only larger organisations may execute such operations. It also leads to self-selection of companies into offshoring depending on their productivity and size. From the economic perspective, it means that all locations are not the same. There is still room for improvement in order to compete for new projects.

\subsection{Agglomeration economies and advanced business services}

Agglomeration economies, that is, the positive externalities stemming from clustering in a geographic location are confirmed to improve the performance of firms. Three types of agglomerations economies were described by Marshal (1920): knowledge 
spillovers from other firms, pool of specialised labour created by industry demand, and pool of other inputs as a result of industry demand. Indeed, an important element of his approach was the role of a firm.

The pioneers in the new economic geography (NEG) assumed that firms are homogenous (e.g. Krugman, 1991). However, such an approach is not in line with the vast evidence that firms are different by many characteristics. The most important is the productivity. It is also confirmed that firms cluster in areas of the high value of GDP, which indicates the large size of an economy. Agglomeration economies lead to uneven distribution of businesses across geographic units. This is a force that strengthens the strongest regions and diminish the probability of locating a new business in weaker regions. Anyway, only the most productive firms gain from operations in the most prosperous regions (Baldwin \& Okubo, 2006). To include the heterogeneity of firms they merged the NEG approach with Melitz (2003) model of monopolistic competition. The authors also stated that the standard approach to measuring agglomeration economies overestimates their influence. The productivity gains due to agglomeration economies are questioned as the high level of concentration in a region may have a negative effects on economic performance (Drucker \& Feser, 2012).

When it comes to the geographic scope, the agglomeration economies are predominantly measured on a regional level. Another approach to the agglomeration economies is measuring them on a city level. Behrens, Duranton and Robert-Nicoud (2014) provide evidence on the agglomerating and sorting of firms to operate in large cities. There is also agglomeration among workers. Coniglio (2001) assumes the existence of skill premium as a function of number of skilled workers in a region. Another example of spatial agglomeration is sorting, which occurs among workers (Combes, Duranton, \& Gobillon, 2004). Most productive workers move to most productive locations thus increasing their productivity even more.

When the agglomeration economies are discussed, the notion of a "global city" should be introduced. It is considered as offering global interconnectedness, cosmopolitanism, and abundance of advanced business services (Goerzen, Asmussen, \& Nielsen, 2013). The notion of a global city does not fully correspond to the meaning of megacities, when the vast population is considered. In the case of a global city it is more important to analyse the business related functions, as being a part of a global value chain. However, the agglomeration at the level of cities is not universally confirmed. According to Coe and Townsend (1998) more important is clustering in the region. This was analysed in the case of South-East region of England and its service-based growth.

There is an evidence that the agglomeration economies occur in a different way in services than in manufacturing. Basile, Benfratello, \& Castellani (2009) analysed the European regions and the factors of attractiveness of a particular region were not connected to the attractiveness of the other regions in the economy. It also means there no direct links to other activities in other regions. They interpreted the 
finding as the lack of exports in services. Actually, when we observe ABS, the lack of cooperation with other regions is rather the result of high exports of services and no need to include partners from other regions. The providers of services are directly linked to their foreign customers.

The technology improvements decrease the necessity of concentration of KIBS in metropolitan areas in order to serve their multinational clients as Keeble and Nachum (2002) or Muller and Doloreux (2009) argued. Indeed, the presence of KIBS units in metropolis or metropole regions is not necessary to provide services to firm located nearby, but rather helps companies reaching foreign clients, for example, the presence of an international airport. We approach agglomeration economies in ABS with respect to MNEs, therefore we need to include global networks in our analysis. Mouleart and Gallouj (1993) put is as "agglomerations in global networks". This is connected to the role of ABS in GVC. Despite the development of communication technologies, KIBS are very prone to concentration is some areas (Shearmur \& Doloreux, 2008; Marek, 2015, p. 42). However, we argue that the recent wave of FDI in ABS in Central and Eastern Europe is different from the earlier development in the Western Europe and forces of agglomeration are weaker. Klimek (2018) used detailed plant-level data, whose advantages were pronounced by Martin, Mayer and Mayneris (2011). However, the meaning of the word "plant" is not fully appropriate for analysing services. Therefore the "office-level approach" was introduced. Indeed, offices are best describing the premises where services are produced. The findings of Klimek (2018) confirm a certain level of agglomeration of ABS in Poland, however it was only due to the concentration of supply factors. It means that locations offering abundance of skilled labour were preferred locations for foreign firms' investment projects. The same study did not find any support for demandside factors, like the size of a local economy measured by the regional GDP.

The conceptual approach to agglomeration of modern business services can be well described as "new geographic concentrations of technical talent and service providers offering upstream technical and knowledge-intensive business services to regional and global clients” (Manning, Ricart, Rosatti Rique, \& Lewin, 2010). They list three main reasons of the development of new locations intensively providing services. The first one is the emergence of local talent pools, which can be tapped and used extensively by MNEs in their global context. Second reason is the need of MNEs to conduct a broader search of talents, also in non-obvious location in emerging economies. The last argument is linked to the emergence of global service providers, which execute their internationalisation strategies by following their global customers and establishing service centres in multiple locations.

There is also an inconsistent evidence regarding the link between financial performance of firms and agglomeration economies (Stavropoulos \& Skuras, 2016). The net level of positive effects stemmed from agglomeration economies depends on the prior characteristics of firms. Those with weak performance gain most from clustering and those with strong performance (and the best assets) have little to 
gain (Myles Shaver \& Flyer, 2000). However, their study is limited in time and employs quite a small sample. There is also the question of whether there are differences in measuring agglomeration in services in comparison to agglomeration in manufacturing (Jones \& Wren, 2016). This confirms the need for detailed analysis of agglomeration economies, especially in business services, which were frequently neglected.

Pooling of firms in the same location may have both positive and negative effects. When it comes to ABS, the positive elements include: pool of qualified workers, proximity to educational institutions, commercial properties market. However, we can also mention the negative aspects, such as: competition for workers or higher rents for property. A firm must consider the overall balance before undertaking FDI in a particular location.

Summing up the theoretical approaches to offshoring of ABS, they range from detailed business frameworks to more general economic models. The main approach is that the models try to explain offshoring, irrespective if it is within the boundaries of a firm or not. We agree with such an approach to the theory, however some governance issues should be also raised.

When considering the theoretical background of offshoring of white-collar jobs we have to avoid oversimplification and stereotypes present in the public discussion regarding the process. For a home economy it is pictured as losing jobs and crucial competencies, while for a host economy it is presented as exploitation of cheap skills. The knowledge-intensive services that are provided in the global network are far from this approach. Unfortunately, it is still dominant strain in the policy discussion, but also in many business studies. The proper conceptual framework and theoretical models of offshoring are crucial for analysing the policy implications of offshoring. Without such a base, there are many inconsistent and inconclusive results expected. Again we come back to the issue of defining and measuring not only ABS, but services in general. The new statistical approach is necessary to understand the role of ABS in the global and domestic economies.

All in all, we argue that due to the dynamic changes in the ABS industry, the universal model is far from being prepared. The evolution of the industry is related to the rising complexity of modes, forms and networks that provide business services. The participants of ABS are changing and next to human workers there is a rising role of robots, and artificial intelligence solutions. 